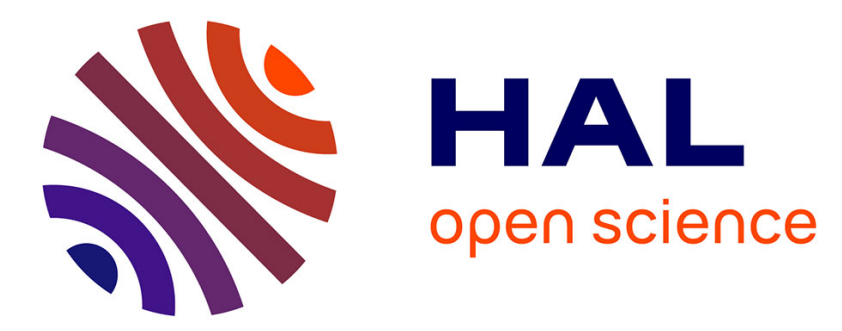

\title{
The challenges of applying an Activity-Based Sampling methodology to estimate the cancer risk associated with asbestos contaminated landfilled zones
}

María Fernanda Cely-García, Benjamin Lysaniuk, Roberto Pasetto, Juan Pablo Ramos-Bonilla

\section{To cite this version:}

María Fernanda Cely-García, Benjamin Lysaniuk, Roberto Pasetto, Juan Pablo Ramos-Bonilla. The challenges of applying an Activity-Based Sampling methodology to estimate the cancer risk associated with asbestos contaminated landfilled zones. Environmental Research, 2020, 181, pp.108893. 10.1016/j.envres.2019.108893 . halshs-02539156

\section{HAL Id: halshs-02539156 \\ https://shs.hal.science/halshs-02539156}

Submitted on 17 Jan 2022

HAL is a multi-disciplinary open access archive for the deposit and dissemination of scientific research documents, whether they are published or not. The documents may come from teaching and research institutions in France or abroad, or from public or private research centers.
L'archive ouverte pluridisciplinaire HAL, est destinée au dépôt et à la diffusion de documents scientifiques de niveau recherche, publiés ou non, émanant des établissements d'enseignement et de recherche français ou étrangers, des laboratoires publics ou privés. 


\title{
The Challenges of Applying an Activity-Based Sampling Methodology to Estimate the Cancer Risk Associated with Asbestos Contaminated Landfilled Zones.
}

\author{
María Fernanda Cely-García ${ }^{1}$, Benjamin Lysaniuk², Roberto Pasetto ${ }^{3,4}$ Juan Pablo \\ Ramos-Bonilla ${ }^{1 *}$.
}

1. Department of Civil and Environmental Engineering, School of Engineering, Universidad de Los Andes, Bogotá, Colombia.

2. IRD, UMR Prodig, Paris, France.

3. Department of Environment and Health, Istituto Superiore di Sanità, Rome, Italy.

4. WHO Collaborating Centre for Environmental Health in Contaminated Sites, Istituto Superiore di Sanità, Rome, Italy.

*Corresponding author. Phone: 57-316 840 4250, Fax: 57-1 332 4313, Email: iramos@uniandes.edu.co, Address: Cra 1 este No 19a-40, ML 328, Bogotá, Colombia.

\section{${ }^{1}$ Abbreviations}

\footnotetext{
${ }^{1}$ ABS: Activity-Based Sampling; AC: Actinolite; ACM: Asbestos-containing material; ALAA: Action level for asbestos in air; $\mathrm{CH}$ : Chrysotile; ELCR: Excess Lifetime Cancer Risk; EPC: Exposure Point Concentration; HEPA: High-Efficiency Particulate Air; IARC: International Agency for Research on Cancer; ISO: International Organization for Standardization; LOD: Limit of Detection; LPM: Liters per minute; MCE: Mixed Cellulose Ester; N/A: Not applicable; ND: Non detected; NIOSH: National Institute for Occupational Safety and Health; NVLAP: National Voluntary Laboratory Accreditation Program; PAPR: Powered air-purifying respirator; PCM: Phase Contrast Microscopy; PLM: Polarized Light Microscopy; TEM: Transmission Electron Microscopy; US EPA: United States Environmental Protection Agency; USGS: United States Geological Survey.
} 


\section{Abstract}

Inhabitants of Sibaté (Colombia) report that between approximately 1975 and 1985 asbestos-containing materials (ACM) were dumped at different locations in the urban area of the municipality. Starting in around 1986, the dumping of materials resulted in landfilled zones, on top of which different facilities were then constructed. In a previous study, an underground friable asbestos layer was discovered in these landfilled zones. However, potential exposure to asbestos on the surface of landfilled zones in Sibaté has not been determined. In the current study, the U.S. EPA Activity-Based Sampling (ABS) methodology was adapted and applied in three scenarios located on potential landfilled areas in Sibaté, to estimate the current risk of exposure to asbestos through inhalation, and the resulting excess lifetime cancer risk (ELCR). For this purpose, generic ABS in a football stadium, and specific ABS in both a public playground and a school courtyard were conducted. Personal, area and blank samples were collected and analyzed using phase contrast microscopy (PCM) and transmission electron microscopy (TEM) following NIOSH 7400 and ISO 13794 methods, respectively. Exposure point concentrations were determined and compared against the action level for asbestos in air (ALAA), and were also used to calculate the ELCR of each scenario.

A total of 25 airborne asbestos samples were collected, and 22 of these (12 personal samples, 7 area samples and 3 blank samples) were analyzed using PCM. Eighteen of these samples (12 personal, 3 area samples and 3 blank samples) were analyzed using TEM. The total asbestos structures concentration of personal samples ranged from nondetected to $0.326 \mathrm{~S} / \mathrm{cc}$ (i.e., total asbestos structures counts ranged from 0 to 12). All samples had PCM-Equivalent asbestos structures concentrations below analytical sensitivity. Of the 22 samples analyzed, 18 were overloaded with particles. Although chrysotile and actinolite were identified in some personal samples, suggesting a potential risk of asbestos exposure, the ELCR was at U.S. EPA acceptable risk levels. Since the ABS methodology was applied in a limited number of scenarios and a small number of samples were collected, these results should be interpreted with caution and additional sampling campaigns are required to fully understand the risk of asbestos exposure in Sibaté. Methodological and analytical challenges encountered in the current study are discussed in detail, which could inform future ABS studies, not only in Sibaté, but also in other areas with asbestos-contaminated soils.

\section{Key Words}

Activity-Based Sampling; Excess Lifetime Cancer Risk, Environmental exposure; Asbestos-contaminated landfilled zones; Sibaté; Colombia. 


\section{Funding Sources}

This research was funded with Colciencias Grant 784, 2017 for Postdoctoral Positions in Colombia, Contract FP44842-124-18, and with internal funds from Universidad de Los Andes.

\section{Ethical Considerations}

This study does not involve human subjects. Results used in this study that were obtained previously and involved human subjects were taken from a larger study that was approved by the Universidad de Los Andes Ethics Committee. 


\section{Introduction}

Asbestos refers to several naturally-occurring fibers that are classified into two families: Amphiboles (amosite, crocidolite, tremolite, actinolite and anthophyllite) and Serpentines (chrysotile) (ATSDR, 2001; IARC, 2012). All types of asbestos, including chrysotile, have been classified by the International Agency for Research on Cancer (IARC) as carcinogenic to humans (Group I carcinogens) (IARC, 2012; WHO, 2014). Asbestos exposure causes malignant mesothelioma; cancer of the lungs, larynx and ovaries; and non-carcinogenic diseases including asbestosis (IARC, 2012; WHO, 2014). From a human health perspective, inhalation is the most prevalent route of exposure to asbestos (ATSDR, 2001; WHO, 2014).

A person may be exposed to asbestos in different scenarios (Goldberg \& Luce, 2009), including occupational, environmental or household settings (Goldberg \& Luce, 2009; WHO, 2014). The highest asbestos exposures occur in occupational settings (Goldberg \& Luce, 2009; Mensi, Riboldi, De Matteis, Bertazzi, \& Consonni, 2015; WHO, 2014), which, to date, is the exposure scenario that has been studied in most detail worldwide and comprises the largest number of malignant mesothelioma cases reported (Mensi et al., 2015). However, non-occupational asbestos exposures can result in the development of asbestos-related diseases (Goldberg \& Luce, 2009). Previous studies have shown that non-occupational asbestos exposures resulting from the operation of asbestos cement facilities can have adverse health consequences for the general population, and this has been observed in different parts of the world, including Casale Monferrato (Magnani et al., 2001; Magnani et al., 1995) and Bari (Musti, Pollice, Cavone, Dragonieri, \& Bilancia, 2009) in Italy, and Amagasaki in Japan (Kumagai \& Kurumatani, 2009; Kurumatani \& Kumagai, 2008).

In Colombia, asbestos exposure concentrations and health risks have been previously studied in occupational settings, specifically for automotive mechanics (CelyGarcía, Curriero, Giraldo, et al., 2016; Cely-García, Curriero, Sánchez-Silva, et al., 2016; Cely-García, Sánchez, Breysse, \& Ramos-Bonilla, 2012; Cely-Garcia et al., 2014; Salazar, Cely-García, Breysse, \& Ramos-Bonilla, 2014). Only one study has been carried out in Colombia addressing the consequences of asbestos use and health effects at population level (Ramos-Bonilla et al., 2019). The study was conducted in the municipality of Sibaté and establishes the framework for the current study.

In 1942, an asbestos-cement facility began operations in Sibaté (Eternit, 2019). At the time, Sibaté was part of a larger municipality called Soacha, and it became a separate municipality in 1967 (Alcaldía, 2018). Sibaté is located 25 kilometers southwest of Bogotá, the capital of Colombia. Adjacent to the urban area of Sibaté is El Muña Reservoir (Alcaldía, 2018), which receives untreated waters from the heavily polluted Bogotá river. In 2018, the estimated population of Sibaté was 40,535 (DANE, 2019). Figure 1 shows the location of Sibaté, Soacha, some southern-most neighborhoods of Bogotá, El Muña Reservoir, and the asbestos-cement facility. Sibaté inhabitants have been claiming in the national media (television and print media) that a large number of people from the 
municipality are being diagnosed with asbestos-related diseases (Ramos-Bonilla et al., 2019). In January 2015, for the first time, a study was started to investigate the public health situation in Sibaté (Ramos-Bonilla et al., 2019). This initial study collected preliminary information on the health and socio-economic situation of Sibaté, applying 355 household surveys. The surveys, completed between June 2015 and June 2016, were aimed at identifying the possible cases of patients diagnosed with asbestos-related diseases (especially mesothelioma), and potential sources of asbestos exposure (RamosBonilla et al., 2019). Respondents reported the presence of landfilled zones that were filled with asbestos-containing materials (ACM) in the urban area of Sibaté. On April $28^{\text {th }} 2018$, a participatory workshop was held to reconstruct the history of the landfilled zones based on the collective memory of a group of Sibaté inhabitants. The information provided by the workshop participants $(n=11)$ suggested that some areas in Sibaté were used to dump asbestos-containing materials from the mid 70 s to the mid 80 s. Also, they reported that after approximately 1986, this material was used to level the ground of landfilled zones, on top of which the municipality constructed different facilities including two football fields (a stadium and a football field with athletic track), a bull-fighting ring and part of a public school (Ramos-Bonilla et al., 2019). Universidad de Los Andes Ethics Committee approved the survey and the workshop, and the informed consent form that was signed by all participants. Ethical issues, including study participants' anonymity, were addressed, and measures to minimize risks related to a person's participation in the study (e.g., psychological distress) were taken. Moreover, attention was paid to the communication of the study procedures and risk to the exposed community in line with the "do no harm" principle. 


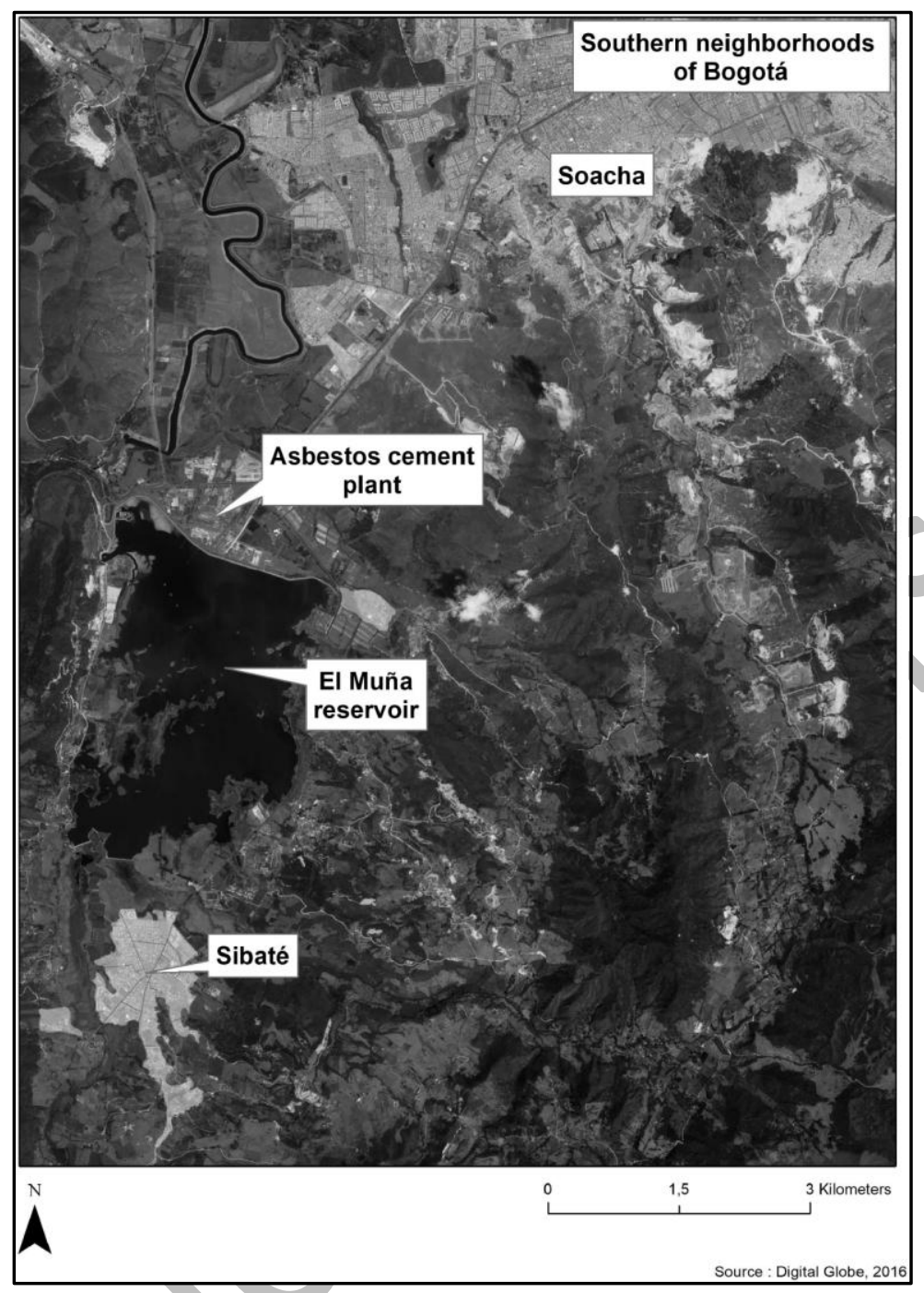

Figure 1. Location of Sibaté, El Muña Reservoir, the asbestos cement plant, Soacha, and some southern neighborhoods of Bogotá.

Complementing the information obtained from Sibaté's inhabitants, potential landfilled zones in Sibaté's urban area were identified using geographic information systems (GIS) that integrated topographic maps, satellite images and a digital elevation model (Ramos-Bonilla et al., 2019). The results from the GIS were merged with the results of the participatory workshop to determine the location of "probable" and "possible" landfilled areas (Ramos-Bonilla et al., 2019). It is more likely that asbestos will be found in "probable" landfilled zones $(2.8 \mathrm{Ha})$ as they are located in areas that were previously covered by the waters of El Muña Reservoir but have since been replaced with other types of land use (e.g., sports facilities) (Ramos-Bonilla et al., 2019). It is more uncertain that asbestos will be found in "possible" landfilled zones (23 Ha) because these were mostly identified by the presence of topographic depressions (Ramos-Bonilla et al., 2019). In order to confirm the presence of asbestos material in potential landfilled zones, soil samples were collected at four sites (1- outside the stadium, 2- inside the public school, 3on the football field with athletic track, and 4- outside the football field with athletic track) 
(Ramos-Bonilla et al., 2019). Figure 2(a) shows the location of the "probable" and "possible" landfilled areas and the four points where soil samples were collected. A layer of friable asbestos was discovered in the soil samples collected outside the stadium, inside the public school, and on the football field with an athletic track, at a depth ranging between 35 and $110 \mathrm{~cm}$ (Ramos-Bonilla et al., 2019). The asbestos content of the friable asbestos layer ranged from $5 \%$ to $10 \%$ chrysotile and $2 \%$ crocidolite. Non-friable ACM were also found, with an asbestos concentration ranging from non-detected (ND) to $10 \%$ chrysotile and $2 \%$ crocidolite (Ramos-Bonilla et al., 2019). Soil samples were also collected, with an asbestos content ranging from ND to $2 \%$ chrysotile (Ramos-Bonilla et al., 2019). It is important to mention that in the second semester of 2018, excavations to replace underground pipelines were carried out in potential landfilled zones in the vicinity of the areas that would be sampled in the context of the current study. Therefore, a strategy was implemented to assess whether there could be a potential influence of the excavations on the results of this study, as explained below in the Methods and Results sections.

Because asbestos minerals present in soil can potentially become airborne, the United States Environmental Protection Agency (U.S. EPA) developed a methodology called Activity-Based Sampling (ABS), which can be used to quantify asbestos concentration on the surface of areas with soil contaminated with man-made and/or naturally-occurring asbestos (NOA) (EPA, 2019). ABS consists of collecting airborne asbestos personal samples at surface level during the disturbance of soil in asbestoscontaminated areas (EPA, 2007, 2008). There are two types of ABS, generic ABS and specific ABS (EPA, 2007, 2008). Generic ABS instructs for the soil to be disturbed in marked-off areas using a rake, while specific ABS mimics activities that are conducted or will be conducted on a specific area (e.g., running, gardening, a child playing on the ground, among others) (EPA, 2007, 2008). Previous studies have applied ABS in areas with asbestos-contaminated soils, including Sumas Mountain, Washington (USA) (Wroble, 2010; Wroble, Frederick, Frame, \& Vallero, 2017) and Libby, Montana (USA) (EPA, 2010a, 2010b; Ryan et al., 2015). A study in Balangero (Italy) simulated farming activities, but its methodology is not classified as ABS because of the analytical methods used (Turci et al., 2016).

Since the current risk of asbestos exposure on landfilled zones in Sibaté has not been determined, the aims of this study are to adapt and apply the U.S. EPA ABS methodology in these zones of Sibate to determine 1) the risk of exposure to asbestos through inhalation at surface level and 2) the risk of developing lung cancer and mesothelioma as a result of this potential exposure. The challenges of applying the U.S. EPA ABS methodology are also discussed.

\section{Methods}

The sites selected for ABS application were identified using two main criteria: first, the scenarios should be located on or nearby potential landfilled areas since they are more likely to have a friable asbestos layer present (Ramos-Bonilla et al., 2019), and second, 
areas should be used by vulnerable individuals, such as children. Thus, an area within the stadium, a children's playground located near the stadium (both scenario locations are close to Soil Sampling Site 1 - Figure 2), and a courtyard inside a public school (close to Soil Sampling Site 2 - Figure 2) (Ramos-Bonilla et al., 2019) were selected. In both Soil Sampling Sites 1 and 2, the presence of the friable asbestos layer had been confirmed previously (Ramos-Bonilla et al., 2019). Figure 2(b) provides a detailed representation of the areas where ABS campaigns were conducted.

The ABS campaigns were conducted during dry conditions, making sure that there had been at least 3 days without rain before sampling. Since Sibaté does not have a weather station, this was evaluated by asking Sibaté residents who collaborated with the study whether precipitation events had occurred during the 3 days preceding the ABS campaign.

The three ABS campaigns were conducted over 2 days by 3 researchers who wore complete personal and respiratory protection equipment that included Tyvek suits with shoe covers, gloves and Bullard hooded EVA Series Powered air-purifying respirators (PAPR) with Bullard High-Efficiency Particulate Air (HEPA) Filter Cartridges (Bullard, Cynthiana and Lexington, KY, U.S.). Each researcher also wore one or two personal AIRCheck XR5000 air pumps (SKC, Eighty Four, PA, U.S.), connected with tubing to a 25 $\mathrm{mm}$ asbestos sampling cassette with a conducting extension cowl of $50 \mathrm{~mm}$, which carried a $25 \mathrm{~mm}$ mixed cellulose ester (MCE) filter with a pore size of $0.45 \mu \mathrm{m}$ (SKC Preloaded Cassette, SKC). The sampling cassette was located in the respiratory zone of each researcher. Personal samples were collected at a flow rate of $\sim 2.0$ or $\sim 2.9$ liters per minute (LPM), calibrated on site at the beginning and end of each sampling window with a Defender 520 MesaLabs Flow Calibrator (MesaLabs, Lakewood, CO, U.S.). Temperature and relative humidity were recorded each minute during sampling campaigns using a HOBO U10-003 Temperature Relative Humidity Data Logger (ONSET, Bourne, MA, U.S.). One or 2 area samples per scenario were collected at 2.0 or $\sim 2.9$ LPM following the previously described procedures, using sampling tripods to place the sampling cassettes at a respiratory height of $1.5 \mathrm{~m}$. One blank sample was also analyzed for each scenario. 


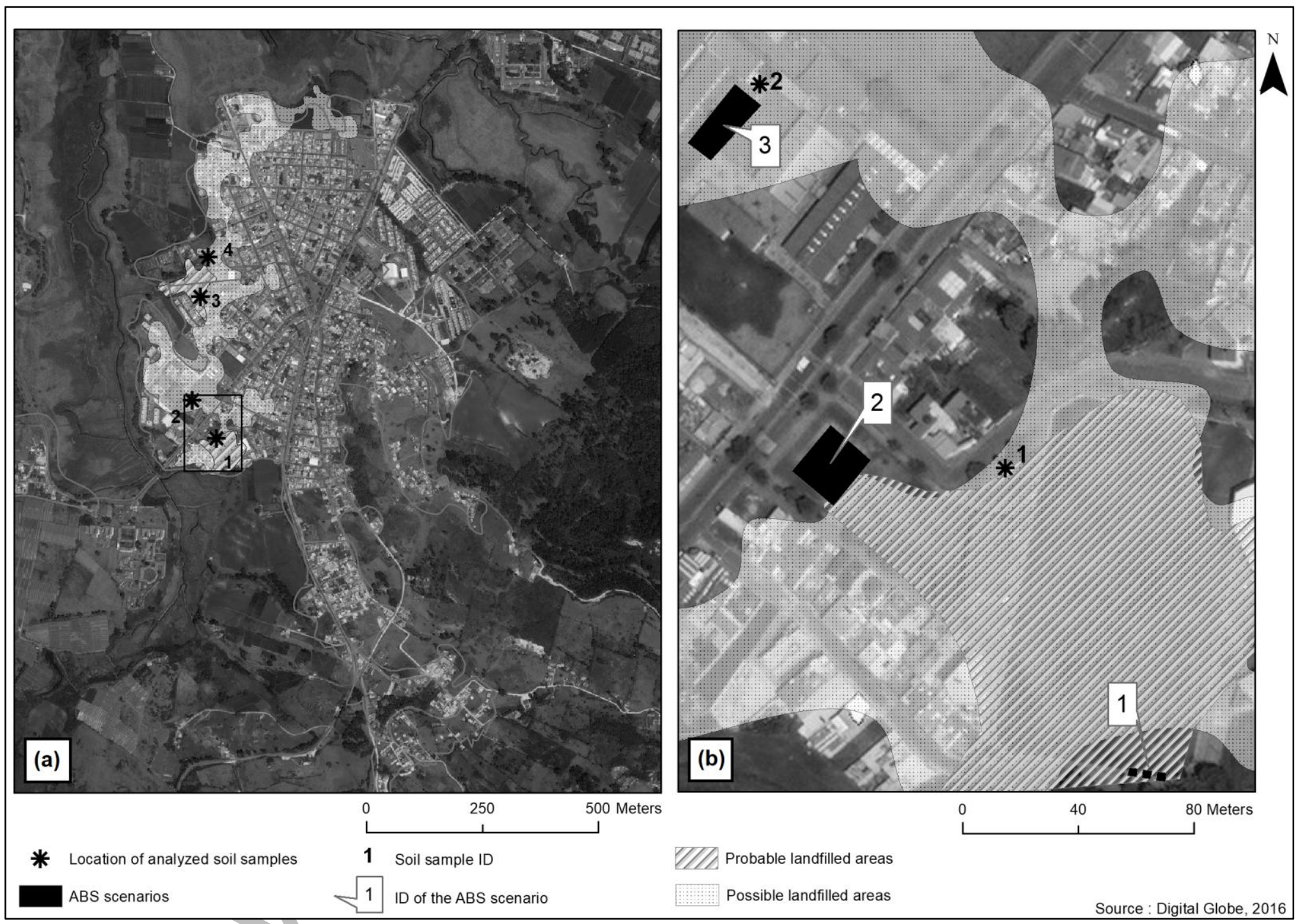

Figure 2(a) shows the location of the "probable" and "possible" landfilled areas and the soil sampling sites covered by the research team. Figure 2(b) shows in detail the ABS scenarios evaluated close to Soil Sampling Sites 1 and 2. 
All disposable elements used during sampling campaigns were moistened with a mixture of soap and water and packed into a hazardous materials bag, which was properly labeled and disposed of by the Solid Waste Laboratory at Universidad de Los Andes.

On November $23^{\text {rd }} 2018$, the first ABS campaign was conducted at the stadium, following Generic ABS procedure, where 3 square surface areas of $9 \mathrm{~m}^{2}$, located side by side and separated $2 \mathrm{~m}$ from each other, were sampled. The 3 areas were located behind one of the goals on the football field so as to be as far away as possible from the excavations that had been conducted to replace pipelines, while still remaining within the stadium. The 3 areas also had a $40 \mathrm{~m}$ buffer distance to the nearest house. In each square area sampled, the soil on the surface was disturbed vigorously using a $58 \mathrm{~cm}$-wide leaf rake following the method of disturbance proposed by the U.S. EPA (EPA, 2007, 2008). The plan was to sample 3 areas, collecting one personal sample at each square sampled. Each researcher wore one personal sampler at 2.9 LPM and the campaign was planned to last $\sim 3$ hours to reach a target volume of 560 Liters (L), which would result in a sensitivity limit of 0.001 structures per cubic centimeter (S/cc), following the recommendations of the U.S. EPA guidelines for ABS (EPA, 2007). When one of the personal pumps failed, the decision was to continue sampling on the remaining two square areas, which allowed one researcher to take over from the other two in the sampling task. This procedure is described in the U.S. EPA ABS guidelines (EPA, 2007, 2008). A perimeter air area sample was also collected at $\sim 2.9$ LPM during a time window of $\sim 3$ hours.

The second ABS campaign was conducted on December 11, 2018, following the procedures for Specific ABS, simulating a "child playing in the dirt" (EPA, 2007; 2008) at a playground near the stadium and in a courtyard located within the public school. For this, two researchers used a new set of children's shovels and buckets in each location to avoid cross contamination. ABS campaigns were conducted over two hours at different points within each location. All the surface area of the playground was covered with sand, while the surface area of the courtyard at the school was covered mostly with grass with some patches of exposed soil. The latter ABS was conducted on patches of exposed soil. In both scenarios, the researchers wore the personal samplers at their respiratory zone, but the activities were conducted sitting on the ground to simulate the height of a child. Since overloading was an issue during the Generic ABS conducted at the stadium (i.e., the results from the phase contrast microscopy-PCM of the first ABS were available before the second ABS campaign), a new sampling strategy was applied: in both ABS-specific scenarios, only two researchers wore the samplers and the third researcher periodically changed the sampling cassettes and conducted flow calibration of the pumps, kept activity diaries, and aided the overall ABS process. Each researcher wore two samplers operating simultaneously, one running at 2 LPM and the other running at $~ 2.9$ LPM. Sampling time ranged between 1 and 2 hours. Two perimeter area samples were collected at both locations at a flow rate of $\sim 2.9$ LPM over 1 or 2 hours. 
All air samples (area, personal and blank filters) were analyzed by Forensic Analytical Laboratories (Hayward, CA, U.S.) - a laboratory accredited by the National Voluntary Laboratory Accreditation Program (NVLAP)—using PCM following the National Institute for Occupational Safety and Health method 7400 (NIOSH 7400) (NIOSH, 1994). The original plan was to analyze the samples following the International Organization for Standardization (ISO) Direct Method ISO 10312 (ISO, 1995). However, PCM results showed that all but 4 samples (1 area sample and the 3 blank samples) were overloaded, and because of this, ISO 10312 could not be applied. Thus, all personal and blank samples, and some area samples (i.e., those with the largest number of fibers identified by PCM and the only sample that was not overloaded) were analyzed following the indirect method ISO 13794 (ISO, 1999) using a Philips CM12 Transmission Electron Microscope (FEI Corp, Hillsboro OR, U.S.), which identifies the concentration of asbestos structures per cubic centimeter (S/cc) using transmission electronic microscopy (TEM). This protocol counts all structures containing asbestos fibers longer than $0.5 \mu \mathrm{m}$ and that have aspect ratios greater than 3:1 at an accelerating voltage of $100 \mathrm{keV}$ and a magnification of $\times 18,500$, to achieve precise measurements that confirm the dimensions of asbestos structures close to the method limits. Energy Dispersive X-ray analysis (EDXA; NORAN System 7, Thermo Fisher Scientific, Madison, WI, U.S.) was used for elemental composition analysis. Qualitative Selected Area Electron Diffraction (SAED) was used to observe the crystal structure of individual fibers. In all samples analyzed by TEM, $289 \mathrm{~mm}^{2}$ of the filter area was ashed (total filter area $=385 \mathrm{~mm}^{2}$ ), the resuspension volume was 45 $\mathrm{ml}$, the volume filtered was $34 \mathrm{ml}$, the re-filtration area was $190 \mathrm{~mm}^{2}$, the grid opening (GO) area was 0.0090 or $0.0091 \mathrm{~mm}^{2}$, and the number of GOs analyzed was 10 .

Personal PCM-equivalent asbestos structures reported per scenario were used as the exposure point concentration (EPC) for each scenario $i$ (EPA, 2008), because this concentration type quantitatively evaluates the potential asbestos health risks (EPA, 2007, 2008; Wroble, 2010). When more than one PCM-Equivalent asbestos concentration was obtained, the time-weighted average was estimated and used as the $\mathrm{EPC}_{\mathrm{i}}$. For those cases in which the PCM-equivalent asbestos concentration was below the limit of detection, $0 \mathrm{~S} / \mathrm{cc}$ had to be used for calculation purposes (EPA, 2008). EPC $\mathrm{i}_{\mathrm{i}}$ was compared against the Action Level for Asbestos in Air $\left(A L A A_{i}\right)$ per scenario. $A L A A_{i}$ was calculated using Equation 1 (EPA, 2008).

$$
A L A A_{i}=(\text { Target risk level }) /\left(T W F_{i}{ }^{*} I U R_{L T L i}\right)
$$

Equation 1 (EPA, 2008)

Where the target risk recommended by the U.S. EPA for Baseline Residential Asbestos exposure is $1 \times 10^{-4}$ (EPA, 2008), the $T W F_{i}$ is the scenario-specific time weighting factor that determines the duration and frequency of the exposure per year, and the IUR $R_{L T L i}$ is the less-than-lifetime scenario-inhalation unit risk, which is the inhalation value determined by the U.S. EPA that depends on the age at first exposure and the number of years of exposure (EPA, 2008). $T W F_{i}$ and IUR $R_{L T L i}$ are calculated depending on the activities conducted in each scenario, the age of the population that could be exposed in each scenario, and the "Extrapolated Unit Risk Values for Continuous and Less-ThanLifetime Exposures" reported by the U.S. EPA in the ABS method guidelines (EPA, 2008). 
Scenario-Excess Lifetime Cancer Risk $\left(E L C R_{i}\right)$ was calculated using the $E P C_{i}$ calculated and the $T W F_{i}$ and the $I U R_{L T L i}$ assumed for each scenario, using Equation 2 (EPA, 2008).

$$
E L C R_{i}=E P C_{i}{ }^{*} T W F_{i}{ }^{*} I U R_{L T L i} \quad \text { Equation } 2(E P A, 2008)
$$

Superficial soil samples were also collected in the patches without grass in the courtyard at the school where the specific ABS was conducted. Superficial soil samples were analyzed by Forensic Analytical Laboratories, following U.S. EPA Method 40 CFR, Part 763, Appendix E to Subpart E, and the U.S. EPA 600/R-93-116 method, Visual Area Estimation, using Polarized Light Microscopy (PLM) (EPA, 1993).

As previously mentioned, before and at the time of the ABS campaigns (second semester of 2018), the municipality undertook major soil excavations to replace underground pipelines, and some of these excavations were carried out on streets located on "probable" and "possible" landfilled zones. Thus, a strategy was implemented to understand the potential impact of the excavations on the results of the ABS campaigns conducted in November and December 2018. On October $19^{\text {th }} 2018,4$ soil samples were collected at different depths from the slopes of 4 of the excavation holes that had been opened on the streets that surround the football stadium. The 4 soil samples were analyzed using PLM following the U.S. EPA Method 40CFR, Part 763, Appendix E to Subpart E and U.S. EPA 600/R-93-116, Visual Area Estimation (EPA, 1993), by Forensic Analytical Laboratories. On October $25^{\text {th }} 2018$, when the holes were still open but excavation activities had ceased, 424-hr air asbestos samples were collected from nearby the football stadium to determine airborne asbestos concentrations. Air samples were analyzed by Forensic Analytical Laboratories using PCM following NIOSH method 7400 (NIOSH, 1994) and TEM following the AHERA method (EPA, 1987).

\section{$\underline{\text { Results }}$}

Three ABS campaigns were conducted in Sibaté, very close to 2 of the locations where soil samples confirmed the presence of a friable asbestos layer (outside the stadium and inside the public school) (Ramos-Bonilla et al., 2019). Table 1 presents the sampling characteristics and conditions of each scenario evaluated.

Table 1. Sampling characteristics and conditions per scenario evaluated.

\begin{tabular}{cccccc}
\hline Type of ABS & Scenario & $\begin{array}{c}\text { Total } \\
\text { sampling } \\
\text { time }(\mathrm{hr})\end{array}$ & $\begin{array}{c}\text { Area } \\
\text { sampled } \\
\left(\mathrm{m}^{2}\right)\end{array}$ & $\begin{array}{c}\text { Range of } \\
\text { Temperature } \\
\text { during sampling } \\
\left({ }^{\circ} \mathrm{C}\right)^{2}\end{array}$ & $\begin{array}{c}\text { Range of Relative } \\
\text { Humidity during } \\
\text { sampling }(\%)\end{array}$ \\
\hline Generic & Stadium & $\sim 3.5$ & $\sim 18^{1}$ & $23.5-39.1$ & $27.7-70.9$ \\
\hline Specific & \begin{tabular}{c} 
Playground \\
\cline { 2 - 6 }
\end{tabular} & $\sim 2.5$ & $\sim 182$ & $17.4-26.5$ & $36.8-62.3$ \\
\hline 1. $\begin{array}{c}\text { Courtyard } \\
\text { at the } \\
\text { school }\end{array}$ & $\sim 2.5$ & $\sim 77$ & $23.7-40.0$ & $16.2-44.3$ \\
\hline Only 2 of the 3 planned $9 \mathrm{~m}^{2}$ areas could be sampled. & & & \\
\hline
\end{tabular}


2. This temperature range is abnormally high considering the geographical location of Sibaté, and could be the result of the instrument receiving direct solar radiation.

In the 3 ABS campaigns, a total of 25 airborne samples were collected (15 personal, 7 area and 3 blank samples). All samples, apart from 3 personal samples, were analyzed by PCM following the NIOSH 7400 method (NIOSH, 1994) (1 sample from the stadium was discarded in the field, "Generic Stadium P1," and 2 samples collected at the school, "Specific CY P1" and "Specific CY P2," were not suitable for analysis because the filter was wet or covered with an unknown substance, according to the laboratory report). From the remaining 22 samples, a total of 18 samples were analyzed by TEM following the ISO 13794 method (ISO, 1999) (12 personal samples, 3 area samples and 3 blank samples). The 4 area samples that were not analyzed by TEM had 0 fibers $(n=3)$ or 0.5 fibers $(n=1)$ based on PCM results. Table 2 shows the PCM and TEM results of airborne samples collected. All PCM concentrations were below the limit of detection (LOD) and the number of fibers counted ranged from 0 to 4 . From the 18 samples analyzed by TEM, it was found that no structures were detected in 8 samples (including the 3 blanks), 1 had both chrysotile and actinolite structures, and the other 9 had chrysotile structures. There were 4 personal samples that had 0 total asbestos structures counted with a total asbestos concentration reported as ND ("Specific PG P2," "Specific PG P3," "Specific PG P4" and "Specific PG P6"), and in the other personal samples, from 1 to 12 total asbestos structures were counted, with total asbestos structures concentrations ranging from 0.006 to $0.326 \mathrm{~S} / \mathrm{cc}$. In all samples, 0 PCM-Equivalent asbestos structures were counted and PCM-equivalent asbestos structures concentration was below analytical sensitivity. Thus, for $\mathrm{EPC}_{\mathrm{i}}$ calculations, $0 \mathrm{~S} / \mathrm{cc}$ was used as the concentration of personal samples (EPA, 2008). 
Table 2. PCM and TEM results of air samples collected during generic and specific ABS.

\begin{tabular}{|c|c|c|c|c|c|c|c|c|c|c|c|c|c|c|c|}
\hline \multirow{3}{*}{$\begin{array}{l}\text { Type of } \\
\text { ABS }\end{array}$} & \multirow{3}{*}{ Scenario } & \multirow{3}{*}{ Sample } & \multirow{3}{*}{$\begin{array}{c}\text { Sampling } \\
\text { time } \\
\text { (min) }\end{array}$} & \multicolumn{4}{|c|}{ PCM } & \multicolumn{8}{|c|}{ TEM } \\
\hline & & & & \multirow{2}{*}{$\begin{array}{l}\text { Volume } \\
(\mathrm{L})\end{array}$} & \multirow{2}{*}{ Fibers } & \multirow{2}{*}{$\begin{array}{l}\text { LOD } \\
\text { F/cC }\end{array}$} & \multirow{2}{*}{$\begin{array}{l}\text { Concentration } \\
\text { (f/cc) }\end{array}$} & \multirow{2}{*}{$\begin{array}{c}\text { Analytical } \\
\text { sensitivity } \\
\text { (S/cc) }\end{array}$} & \multicolumn{3}{|c|}{ \# asbestos structures counted } & \multicolumn{3}{|c|}{$\begin{array}{c}\text { Asbestos structures concentration } \\
\text { S/cc }\end{array}$} & \multirow{2}{*}{$\begin{array}{l}\text { Asbesto } \\
\text { type } \\
\text { detecteo }\end{array}$} \\
\hline & & & & & & & & & Total & $>5 \mu \mathrm{m}$ length & PCM-Eq & Total & $>5 \mu \mathrm{m}$ length & PCM-Eq & \\
\hline \multirow{5}{*}{ Generic } & \multirow{5}{*}{ Stadium } & Generic Stadium $\mathrm{P} 1^{1}$ & --- & --- & --- & --- & --- & --- & --- & --- & -- & -7 & --- & --- & --- \\
\hline & & Generic Stadium P2 ${ }^{2,3}$ & 193 & 575.9 & 1.0 & 0.005 & $<0.005$ & $0.006^{7,8}$ & 6 & 0 & 0 & 0.034 & $<0.006$ & $<0.006$ & $\mathrm{CH}$ \\
\hline & & Generic Stadium $\mathrm{P}^{2}$ & 199 & 577.9 & 3.0 & 0.005 & $<0.005$ & 0.006 & 1 & 0 & 0 & 0.006 & $<0.006$ & $<0.006$ & $\mathrm{CH}$ \\
\hline & & Generic Stadium $\mathrm{A} 1^{2}$ & 219 & 635.8 & 0.0 & 0.004 & $<0.004$ & --- & --- & & & --- & --- & --- & --- \\
\hline & & Generic Stadium $B^{3}$ & --- & 0.0 & 0.0 & -- & -- & $N / A^{8}$ & 0 & 0 & 0 & $\mathrm{~N} / \mathrm{A}$ & $N / A$ & $N / A$ & ND \\
\hline \multirow{20}{*}{ Specific } & \multirow{10}{*}{ Playground } & Specific PG P1 ${ }^{2}$ & 120 & 243.6 & 1.0 & 0.011 & $<0.011$ & $0.015^{8}$ & 6 & 0 & 0 & 0.092 & $<0.015$ & $<0.015$ & $\mathrm{CH}$ \\
\hline & & Specific PG P2 ${ }^{2}$ & 120 & 351.4 & 0.0 & 0.008 & $<0.008$ & 0.010 & & 0 & 0 & $<0.010$ & $<0.010$ & $<0.010$ & ND \\
\hline & & Specific PG P3 ${ }^{2}$ & 61 & 129.1 & 1.0 & 0.021 & $<0.021$ & $0.029^{8}$ & & 0 & 0 & $<0.029$ & $<0.029$ & $<0.029$ & ND \\
\hline & & Specific PG P4 ${ }^{2}$ & 67 & 192.4 & 1.5 & 0.014 & $<0.014$ & 0.019 & 0 & 0 & 0 & $<0.019$ & $<0.019$ & $<0.019$ & ND \\
\hline & & Specific PG P5 $5^{2,4}$ & 61 & 91.5 & 1.5 & 0.029 & $<0.029$ & 0.040 & 2 & 0 & 0 & 0.081 & $<0.040$ & $<0.040$ & $\mathrm{CH}, \mathrm{AC}$ \\
\hline & & Specific PG P6 $6^{2,4}$ & 61 & 143.2 & 1.0 & 0.019 & $<0.019$ & $0.026^{8}$ & 0 & 0 & 0 & $<0.026$ & $<0.026$ & $<0.026$ & ND \\
\hline & & Specific PG $A 1^{2,5}$ & 120 & 347.4 & 3.0 & 0.008 & $<0.008$ & 0.011 & 1 & 0 & 0 & 0.011 & $<0.011$ & $<0.011$ & $\mathrm{CH}$ \\
\hline & & Specific PG $A 2^{2}$ & 60 & 172.6 & 0.0 & 0.016 & 0016 & --- & --- & --- & --- & --- & --- & --- & --- \\
\hline & & Specific PG $A 3^{2,4}$ & 60 & 174.1 & 1.5 & 0.015 & $<0.015$ & 0.021 & 4 & 0 & 0 & 0.085 & $<0.021$ & $<0.021$ & $\mathrm{CH}$ \\
\hline & & Specific PG B & --- & 0.0 & 0.0 & & & $N / A^{8}$ & 0 & 0 & 0 & $\mathrm{~N} / \mathrm{A}$ & $\mathrm{N} / \mathrm{A}$ & $\mathrm{N} / \mathrm{A}$ & ND \\
\hline & \multirow{10}{*}{$\begin{array}{l}\text { Courtyard } \\
\text { at the } \\
\text { school }\end{array}$} & Specific CY $P 1^{6}$ & 120 & 260.6 & $-\overline{-}$ & & -- & --- & --- & --- & --- & --- & --- & --- & --- \\
\hline & & Specific CY P2 $2^{4,6}$ & 120 & 249.0 & & & --- & --- & --- & --- & --- & -- & --- & --- & --- \\
\hline & & Specific $\mathrm{CY} \mathrm{P}^{2}$ & 60 & 124.5 & 0.5 & 0.022 & $<0.022$ & $0.030^{8}$ & 10 & 0 & 0 & 0.299 & $<0.030$ & $<0.030$ & $\mathrm{CH}$ \\
\hline & & Specific CY P4 ${ }^{2}$ & 60 & 169.0 & 4.0 & 0.016 & $<0.016$ & 0.022 & 5 & 0 & 0 & 0.109 & $<0.022$ & $<0.022$ & $\mathrm{CH}$ \\
\hline & & Specific CY $P 5^{2,4}$ & 60 & 135.8 & 0.0 & 0.020 & $<0.020$ & 0.027 & 12 & 0 & 0 & 0.326 & $<0.027$ & $<0.027$ & $\mathrm{CH}$ \\
\hline & & Specific CY P6 $6^{2,4}$ & 60 & 90.4 & 1.5 & 0.030 & $<0.030$ & $0.041^{8}$ & 3 & 0 & 0 & 0.124 & $<0.041$ & $<0.041$ & $\mathrm{CH}$ \\
\hline & & Specific CY $A 1^{2,4}$ & 123 & 262.9 & 0.0 & 0.010 & $<0.010$ & --- & --- & --- & --- & --- & -- & --- & --- \\
\hline & & Specific CY A2 & 60 & 173.6 & 0.5 & 0.016 & $<0.016$ & $0.021^{8}$ & 0 & 0 & 0 & $<0.021$ & $<0.021$ & $<0.021$ & ND \\
\hline & & Specific CY $A 3^{2,4}$ & 59 & 138.4 & 0.5 & 0.019 & $<0.019$ & --- & --- & --- & --- & --- & --- & --- & --- \\
\hline & & Specific CY B & --- & 0.0 & 0.0 & --- & --- & $N / A^{8}$ & 0 & 0 & 0 & $\mathrm{~N} / \mathrm{A}$ & $\mathrm{N} / \mathrm{A}$ & $N / A$ & ND \\
\hline
\end{tabular}

CH: Chrysotile, AC: Actinolite, ND: Non Detected, N/A: Not Applicable

1. Pump stopped working during sampling campaign and the sample was discarded. 
2. Filter loaded with particulate, which may affect analytical result.

3. Apparently the sample labels were switched. This was corrected based on the analytical results.

4. Sample is reported but should not be considered because of flow drift $>5 \%$.

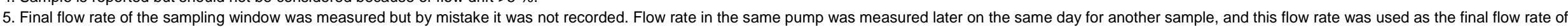
this sample.

6. Not suitable for analysis. Wet filter/coated with unknown substance.

7. For the laboratory analysis of all but this sample, the volume filtered was $34 \mathrm{ml}$. For this specific sample the volume filtered was $39 \mathrm{ml}$

8. Grid Opening area of these filters was $0.0090 \mathrm{~mm}^{2}$. For all other samples, the grid opening area of the filter was $0.0091 \mathrm{~mm}^{2}$. 
Table 3 shows the $\mathrm{EPC}_{\mathrm{i}}$ calculated for each scenario, the assumptions made for $\mathrm{TWF}_{\mathrm{i}}$ and $I_{L T R}$ estimations, and the $A L A A_{i}$ and $E_{L C C}$ calculated. For all scenarios, the PCMequivalent $\mathrm{EPC}_{\mathrm{i}}$ was below the $A L A A_{i}$, and the excess lifetime cancer risk was at U.S. EPA acceptable risk levels.

Table 3. Action Level for Asbestos in Air $\left(A L A A_{i}\right)$ and Excess Lifetime Cancer Risk $\left(E L C R_{i}\right)$ estimated per scenario.

\begin{tabular}{|c|c|c|c|c|c|c|c|c|c|c|c|}
\hline \multirow[b]{2}{*}{$\begin{array}{c}\text { Type of } \\
\text { ABS }\end{array}$} & \multirow[b]{2}{*}{ Scenario } & \multirow[b]{2}{*}{ Assumptions } & \multirow[b]{2}{*}{$E P C_{i}$} & \multicolumn{3}{|c|}{$\mathrm{TWF}_{\mathrm{i}}$} & \multicolumn{3}{|c|}{$\mathrm{IUR}_{\mathrm{LTLi}}$} & \multirow[b]{2}{*}{$\mathrm{ALAA}_{\mathrm{i}}{ }^{2}$} & \multirow[b]{2}{*}{$\mathrm{ELCR}_{\mathrm{i}}$} \\
\hline & & & & Hours / day & Days / year & TWF & $\begin{array}{c}\text { Age at } \\
\text { first expo } \\
(y / 0)\end{array}$ & $\begin{array}{c}\text { Expo } \\
\text { duration } \\
\text { (years) }\end{array}$ & $\begin{array}{l}\operatorname{IUR}^{1} \\
(\mathrm{f} / \mathrm{cc})^{-1}\end{array}$ & & \\
\hline Generic & Stadium & $\begin{array}{l}\text { Young people play football for } 2 \\
\text { hours per week, per year. Based on } \\
\text { exposure scenario } \\
\text { "Running/Walking" proposed by the } \\
\text { U.S. EPA (2008) (EPA, } 2008 \text { ), the } \\
\text { age of first exposure is } 20 \mathrm{y} / 0 \text { and } \\
\text { the duration of exposure is } 24 \text { years. }\end{array}$ & 0 & 2 & 52 & 0.012 & & 24 & 0.068 & 0.124 & 0 \\
\hline \multirow[b]{2}{*}{ Specific } & Playground & $\begin{array}{l}\text { Children play at the park for one } \\
\text { hour per day, three times per week. } \\
\text { Children start playing with sand from } \\
\text { around } 1 \mathrm{y} / \mathrm{o} \text { until their } 10^{\text {th }} \text { birthday. }\end{array}$ & 0 & 1 & & & 1 & 10 & 0.081 & 0.069 & 0 \\
\hline & $\begin{array}{l}\text { Courtyard at } \\
\text { the School }\end{array}$ & $\begin{array}{l}\text { Children have } 1 \text { one-hour break per } \\
\text { day, during the } 200 \text { school days per } \\
\text { year for Colombian public schools } \\
\text { (MinEducación, } 2019 \text { ). Children from } \\
5 \text { to } 10 \text { y/o may play at the area } \\
\text { sampled. }\end{array}$ & 0 & 1 & 200 & 0.023 & 5 & 5 & 0.039 & 0.112 & 0 \\
\hline
\end{tabular}

$\mathrm{TWF}_{\mathrm{i}}$ : Time weighting factor per scenario $\mathrm{i} ; \mathrm{IUR}_{\mathrm{LTL}}$ : Inhalation Unit Risk for the age at first exposure and exposure duration (i.e., less-than-lifetime) per scenario i; EPC $\mathrm{i}_{\mathrm{i}}$ : Exposure point concentration per scenario $\mathrm{i}$; $A L A A_{\mathrm{i}}$ : Action level for asbestos in air per scenario i; ELCR : Excess lifetime cancer risk for less than lifetime per scenario i.

1. Values reported by EPA (2008) in Table "Extrapolated Unit Risk Values for Continuous and Less-Than-Lifetime Exposures (PCM f/cC)" (EPA, 2008).

2. ALAA calculated using the U.S. EPA recommended target risk E-4 baseline residential action level for asbestos of $1 \times 10^{-4}$.

All superficial soil samples collected from the patches with no grass at the school courtyard were reported as ND by the laboratory.

Regarding the potential effect of the excavations made by the municipality on the results of the ABS campaign, the 4 soil samples collected directly from the slopes of the excavated holes confirmed the presence of a friable asbestos layer in 3 samples (i.e., chrysotile concentrations of $10 \%$ and crocidolite concentrations ranging between $2 \%$ and $5 \%$ ). The fourth sample was reported by the laboratory as "dark brown soil" with a chrysotile asbestos content of $2 \%$. Therefore, it is certain that the excavations disturbed the asbestos layer. However, the 4 24-hr air samples collected in the area of the excavations had PCM concentrations which were below the LOD, and the TEM concentrations following the AHERA method were below analytical sensitivity.

\section{Discussion}

Total asbestos structures were found in 8 personal samples for all the scenarios evaluated (7 samples had chrysotile, and 1 sample -"Specific PG P5" - had both chrysotile and actinolite) and in 2 area samples. All ABS results were below the estimated $A L A A_{i}$ and 
the $\mathrm{ELCR}_{\mathrm{i}}$ was at U.S. EPA acceptable risk levels, because the PCM-Equivalent asbestos structures concentrations found for all scenarios evaluated were below analytical

sensitivity. However, these results should be interpreted with caution. Because of the small number of scenarios studied and samples collected, the results cannot be generalized to all the scenarios, situations and activities that may be present in landfilled zones in Sibaté. Thus, from these preliminary results it should not be concluded that there is currently no risk of asbestos exposure related to landfilled zones. Moreover, since the users of the facilities sampled are children and young adults, these results warrant additional analysis of the risk of asbestos exposure on the surface of landfilled zones. Until a more comprehensive estimate of the risks of asbestos exposure in landfilled zones is reached, extreme caution and risk management procedures should be implemented for all activities conducted on potential landfilled zones in Sibaté.

Previous studies applying ABS report a large number of samples collected and PCM-Equivalent asbestos concentrations ranging between 0 and 10.45 S/cc, which are higher than those found in this study (bearing in mind the differences in the activities conducted and the analytical methods used) (Ryan et al., 2015; Wroble, 2010; Wroble et al., 2017). Another ABS conducted in public schools in Libby, Montana (U.S.), found total asbestos counts and concentrations below the results found in this study. Of the 60 samples collected, 5 had 1 total asbestos structures counted, and for these 5 samples, total asbestos concentrations ranged between 0.0022 and $0.039 \mathrm{~S} / \mathrm{cc}$. Furthermore, of these 5 samples, 4 had 1 PCM-Equivalent asbestos structures counted, which resulted in PCM-Equivalent asbestos concentrations ranging between 0.0022 and 0.039 S/cc (EPA, 2010b). In the current study, all PCM-Equivalent asbestos concentrations were below analytical sensitivity.

Activity-based sampling is a valid methodology to determine whether there is a risk of airborne asbestos exposure as a result of activities carried out in areas with asbestoscontaminated soils (EPA, 2007, 2008). Nevertheless, it is important to share some of the challenging circumstances and difficulties that were encountered during this study. It is recognized that $A B S$ can be time and work-intensive (Wroble et al., 2017), especially for small sampling teams. This was the case for the ABS campaigns conducted during this study. Since ABS procedures allow sampling devices to be switched between personnel involved in sampling, it is highly recommended to have a large enough group of trained personnel to reduce the duration of $A B S$ activities for each person conducting the sampling.

As suggested in the ABS guidelines, an important consideration is the targeted analytical sensitivity (EPA, 2007; 2008). The desired analytical sensitivity can be reached with a combination of sampling flow rates and time, which determine the number of grid openings on the filter in which fiber counting is conducted. The number of grid openings drastically increases the costs of analysis per sample. Moreover, high flow rates may damage the filters (EPA, 2007) and, depending on the characteristics of the scenarios sampled, may also increase the risk of overloading. In this study, the pumps and filters 
used (pore size $0.45 \mu \mathrm{m}$ ) did not allow an increase in the flow rate above 3 LPM, so the sampling time required to reach the minimum risk assessment sensitivity limit of 0.001 S/cc for ABS samples (EPA, 2007) had to be a minimum of 3 hours. This is strenuous for a small sampling team, considering the cumbersome protective devices that have to be worn, the heat experienced due to the direct solar radiation at this topographic elevation, and the activities that were simulated.

In the first scenario studied - the stadium - a generic ABS was applied. The analysis of the filters showed that all samples but the blank were overloaded. For the two specific ABSs, the sampling time was reduced to 1 or 2 hours to avoid overloading, and each researcher wore 2 samplers at different flow rates, in an attempt to reduce the chances of having to discharge samples because of overloading (1 sample was collected at $~ 2.0$ LPM and the other at 2.9 LPM). However, all samples but 1 area sample and the blanks were overloaded, and because of the length of sampling time, the recommended analytical sensitivity limit was not reached. Overloading not only introduced uncertainty into the results, but also affected the flow rate of the pumps because of pressure drop, which resulted in 8 samples with a flow drift above $5 \%$.

TEM analysis can be carried out following different methods including AHERA, ISO 10312, ISO 13794, and NIOSH 7402, among others. The specific methods reported by the ABS guidelines (i.e., ISO 10312 and ISO 13794) (EPA, 2007; 2008) require a balance between the targeted analytical sensitivity and the particulate concentration found in the filters based on PCM (ISO, 1995; 1999). Samples that have the target analytical sensitivity based on the air volume collected and that are not overloaded (i.e., less than $10 \%$ obscuration of the grid (ISO, 1995)), are suitable for TEM analysis using the direct method ISO 10312 (ISO, 1995). In case of overloading and/or if the analytical sensitivity is not reached, the indirect method ISO 13794 should be applied (EPA, 2007; 2008). Analytical sensitivity for this method can be reached, increasing the number of grid openings, and carrying out additional preparations of the filter, such as ashing the filter and filtering the ashes dispersed in distilled water (ISO, 1999), which drastically increases the price of analysis and waiting time for the results in comparison with the direct ISO 10312 method. As a result, although in the current study ABS samples were originally planned to meet the direct ISO 10312 method's requirements, overloading resulted in the use of the indirect ISO 13794 method. On top of the additional costs, the indirect filter preparations needed may disaggregate bundles and clusters into smaller and more numerous fibers (Breysse, 1991; EPA, 2010a). This disaggregation may result in fibers shorter than $5 \mu \mathrm{m}$, which are excluded from the estimation of PCM-Equivalent asbestos structures, and may also lead to PCM-equivalent asbestos structures concentrations below the analytical sensitivity limit. This could be the case for the samples analyzed in the current study, and this is an additional reason why our results (i.e., ELCR $\mathrm{E}_{\mathrm{i}}$ at U.S. EPA acceptable risk levels) should be interpreted with caution.

Another factor to consider for ABS are discomfort factors such as heat and sunlight, depending on weather conditions, combined with the PPE and sampling 
equipment required, which can make sampling activities exhausting. During sampling campaigns it was found that sunlight and heat also affected the operation of the piston of the flow calibrator. To solve this, calibrators were stored in a bag during sampling campaigns and were used only under shaded conditions as recommended in the Defender 500 Series User Manual (MesaLabs, 2015).

The ABS results cannot be generalized to other scenarios because the airborne asbestos exposures found in a specific area depend on both the asbestos soil content of the area and the activities conducted on top of it (EPA, 2008). The U.S. EPA has identified 4 concerning exposure pathways: "asbestos in indoor dust," "asbestos in soils around a home," "asbestos in fill/soil in recreational areas of a community," and "recreational activities in areas where asbestos naturally occurs (native asbestos)" (EPA, 2008). For Sibaté, all but the last potential pathway are possible as naturally-occurring asbestos has not been identified in Sibaté. In a previous study, some inhabitants of Sibaté reported that they had used asbestos-containing materials disposed of in different areas of the municipality to build the foundations of their houses or to level the floors inside their homes (Ramos-Bonilla et al., 2019). Thus, cumulative exposure assessments, including indoor scenarios, should be analyzed in the future.

In addition to the sampling and analytical issues discussed that might lead to an underestimation of the PCM-Equivalent asbestos structures concentrations, it is important to acknowledge other limitations of this study. First, sampling campaigns were only conducted at a specific time of the year, and second, the number of samples collected per scenario was small. Therefore, there could be an underestimation of the real risk of asbestos exposure and excess lifetime cancer risk in the scenarios sampled.

The strategy of environmental monitoring in Sibaté should be further implemented with the aim of completing the detection and mapping of asbestos-containing material, both outdoors and indoors. The relative weight of circumstances of asbestos exposure for the local population may have changed over time. At present, the major outdoor risk of asbestos exposure seems to be associated with excavation activities in areas with asbestos-contaminated soils. Thus, precautionary strategies should be proposed and adopted in order to avoid dust re-suspension and fiber volatilization in such areas. To complete the preventive interventions for the eradication or reduction of the health risk in Sibaté, activities focused on the identification and verification of past, current and future sources of asbestos exposure should be integrated with the epidemiological surveillance of asbestos-related diseases, especially mesothelioma, as a tracer of asbestos exposure (Algranti et al., 2019).

As mentioned above, asbestos use in Colombia began in 1942, and because of this, there is a concerning legacy of asbestos contamination in the country. Records from the United States Geological Survey (USGS) Mineral Commodity Profile of Asbestos (Virta, 2005) show that in Colombia, the apparent asbestos consumption (i.e., production plus imports minus exports) was 6,836 metric tons in 1960, 15,000 metric tons in 1975, 
17,994 metric tons in 2000 , and 13,118 in 2003 . Using Legicomex, a database of trade and commerce, our research group determined that the amount of raw asbestos consumed (i.e., production plus imports minus exports) in Colombia between 2009 and 2016 ranged between 10,656 and 24,522 tons per year, with a total raw asbestos amount of 145,035 tons used during this period (Ramos-Bonilla et al., 2019). This information is important because besides the asbestos cement plant located in Sibaté, in 1944, 2 additional cement plants were opened in Barranquilla (Atlántico) and Cali (Valle del Cauca) (Eternit, 2019), which are still in operation. There is also an active chrysotile asbestos mine in Campamento, Antioquia and an active asbestos friction products plant in Bogotá. Manizales (Caldas) is another municipality where asbestos cement plants have operated. Thus, the asbestos problem identified in Sibaté may be present in other Colombian municipalities. Since risk estimates are a reliable and cost-effective way of estimating the effects of a source of exposure on population health (Savitz, 2016), this experience may be useful for future ABS efforts in other scenarios in Sibaté, other cities in Colombia, or other countries where asbestos-contaminated soils may be present.

Although the Colombian Congress recently banned asbestos use and production in the country (July 2019), the history of more than 75 years of asbestos consumption has resulted in a negative legacy of asbestos products distributed across the country, which represents a health risk for the population. The definition of the magnitude of the asbestos problem, in terms of the collection or production of relevant information on local asbestos use, its presence in the territory, and its health-related impacts, is one of the key points identified by both the World Health Organization and the International Labour Organization that is needed to develop national programs for the elimination of asbestos-related diseases (ILO-WHO, 2007). In practical terms, this implies the identification of sources of asbestos exposure, the analysis of potential asbestos exposure risks, and the development of epidemiological surveillance for all Colombian sites, including Sibaté, where asbestos-containing products have been manufactured, used and disposed of.

This study is an initial effort to adapt and apply the U.S. EPA ABS methodology in Colombia. As was explained before, these preliminary results should not be interpreted as an absolute absence of risk associated with landfilled zones in Sibaté, and additional studies are required to acquire a more holistic understanding of the situation.

\section{Conflict of Interest}

María Fernanda Cely-García, Benjamin Lysaniuk, Roberto Pasetto and Juan Pablo Ramos-Bonilla have no financial conflict of interest to declare. Juan Pablo Ramos-Bonilla provided expert opinion in the Colombian Senate for the discussion of a law banning asbestos in the country.

\section{Acknowledgements}

We thank Universidad de Los Andes and Colciencias (Grant 784, 2017 for Postdoctoral Positions in Colombia for former Colciencias National Doctoral Students recipients, Contract FP44842-124-18) for the financial support provided for this project. 
We also thank the community that responded to the survey and attended the participatory workshop for the valuable information they provided for this project.

Thank you to Sandra Córdoba, Principal of the Public School in Sibaté, for her support of the participatory workshop and the specific ABS campaign, both conducted at the school. We want to thank the Mayor's office and the Secretary of Health of Sibaté for giving access to the stadium to conduct the generic ABS.

We want to acknowledge Margarita Giraldo, Pietro Comba, Corrado Magnani, Daniela Marsili, and Agata Mazzeo for their valuable suggestions and comments on improving this manuscript.

We also would like to acknowledge the group of undergraduate students of Universidad de los Andes who have contributed to this research: Lorena Melo, Natalia Gómez, Andrea Marú, David Ospina, Giovanni Castellanos, Juliana Pineda, Carlos Andrés Girón, Oscar Galindo, Ana María Barbosa Gómez, Juan Sebastian Barragán Jerónimo, Mariana Cuartas, María Margarita González Guerrero, Joseph Esteban Herrera Ruiz, Carolina López Gómez, Laura Rubio Velandia, Geraldine Suárez Rodríguez, Catalina Valencia Benítez, Fabio Andrés Vanegas, Lina Marcela Valencia Becerra, Juliana Diazgranados Vives, Laura Camila Bernal González, Camilo Andrés Cáceres Tocora, Miguel Alfonso Feijoo García, Oscar Alejandro Guzmán Grimaldo, Juan Camilo León Avendaño, Tania Daniela Martínez Roa, Christian Enrique Rincón Buitrago, Angie Daniela Ruiz Morales, Claraestela Torres Rivero, María Camila Guerrero, Vanessa Mesa, María Paula Rincón, Daniel Gómez, Alexandra García Vega, Nicolás Navarro Acuña, María Alejandra Caro, Manuela Ortega, Danna Lucía Montes, Daniela Rojas, Valentina Ortiz, Sebastián Ortiz, María Fernanda Chávez, Natalia Giraldo, Paola Cantero, Julian Rios, María Paula León, Vanessa Arias, and Felipe Soler.

Finally, we want to acknowledge Forensic Analytical Laboratories for the analysis of our samples.

\section{References}

Alcaldía. Sibaté: pasado, presente y futuro. Available from: http://sibatecundinamarca.gov.co/MiMunicipio/Paginas/Pasado-Presente-y-Futuro.aspx. [Accessed 6th July 2018].

Algranti E, Ramos-Bonilla J, Terracini B, Santana V, Comba P, Pasetto R, Mazzeo A, Cavariani F, Trotta A, Marsili, D. Prevention of Asbestos Exposure in Latin America within a Global Public Health Perspective. Ann Glob Health. 2019;85(1): 1-15. Available from: doi: 10.5334/aogh.2341.

ATSDR. Toxicological profile for asbestos. U.S. Department of Health and Human Services. Atlanta; 2001. Available from http://www.atsdr.cdc.gov/toxprofiles/tp61.pdf.

Breysse PN. Electron Microscopic Analysis of Airborne Asbestos Fibers. Critical Reviews in Analytical Chemistry. 1991;22(3-4): 201-227. Available from: doi:10.1080/10408349108055029.

Cely-García MF, Curriero FC, Giraldo M, Méndez L, Breysse PN, Durán M, Torres-Duque CA, González-García M, Pérez C, Parada P, Ramos-Bonilla, JP. Factors associated with noncompliance of asbestos occupational standards in brake repair workers. Ann Occup Hyg. 2016;60(8): 1020-1035. Available from: doi:10.1093/annhyg/mew028. [Epub ahead of print]. 
Cely-García MF, Curriero FC, Sánchez-Silva, M, Breysse PN, Giraldo M, Méndez L, Torres-Duque CA, Durán M, González-García M, Parada P, Ramos-Bonilla JP. Estimation of personal exposure to asbestos of brake repair workers. J Expo Sci Environ Epidemiol. 2016;27(4): 417-426. Available from: doi:10.1038/jes.2016.76. [Epub ahead of print].

Cely-García MF, Sánchez M, Breysse PN, Ramos-Bonilla JP. Personal Exposures to Asbestos Fibers During Brake Maintenance of Passenger Vehicles. Ann Occup Hyg. 2012;56(9): 985-999. Available from: doi:10.1093/annhyg/mes030.

Cely-Garcia MF, Torres-Duque CA, Durán M, Parada P, Sarmiento OL, Breysse PN, Ramos-Bonilla JP. Personal exposure to asbestos and respiratory health of heavy vehicle brake mechanics. J Expo Sci Environ Epidemiol. 2014;25(1): 26-36. Available from: doi:10.1038/jes.2014.8. [Epub ahead of print].

DANE. Departamento Administrativo Nacional de Estadísticas. Available from: http://www.dane.gov.co/index.php/estadisticas-por-tema/demografia-y-poblacion. [Accessed January 2019].

EPA. Airborne Asbestos Analysis by TEM. Code of Federal Regulations (CFR) Title 40, Part 763 Appendix A to subpart E. Asbestos Hazardous Emissions Redution Act (AHERA). 1987.

EPA. EPA/600/R-93/116. Method for the Determination of Asbestos in Bulk Building Materials. 1993.

EPA. Standard Operating Procedures for Activity Based Air Sampling for Asbestos (SOP 2084). 2007. p. 1-27. Available from: https://semspub.epa.gov/work/HQ/174392.pdf.

EPA. Asbestos Committe of the Technical Review Workgroup of the Office of Solid Waste and Emergency Response. Framework for investigating asbestos-contaminated superfund sites. U.S. EPA. 2008. Available from: https://semspub.epa.gov/work/HO/175329.pdf

EPA. Activity-Based Sampling Summary Report Operable Unit 4. Libby, Montana, Superfund Site. U.S. EPA. 2010a. Available from http://www.epa.gov/region8/superfund/libby/OU4 ABS ResultsSummaryReportJune201 $\underline{0 . p d f}$

EPA. Public Schools Asbestos Sampling Summary Report. Libby, Montana, Superfund Site. U.S. EPA. 2010b.

EPA. What is Superfund? Available from: https://www.epa.gov/superfund/what-superfund. [Accessed January 2019].

Eternit. Historia. Available from: https://www.eternit.com.co/web/eternit/historia. [Accessed January 2019].

Goldberg M, Luce D. The health impact of nonoccupational exposure to asbestos: what do we know? Eur J Cancer Prev. 2009;18(6): 489-503. Available from: doi:10.1097/CEJ.0b013e32832f9bee.

IARC. IARC Monographs on the Evaluation of Carcinogenic Risks to Humans:. Asbestos (chrysotile, amosite, crocidolite, tremolite, actinolite, and anthophyllite). IARC Monographs-Volume 100C.; 2012. [Accessed October 2015].

ILO-WHO. Outline for the Development of National Programmes for Elimination of Asbestos Related Diseases. Geneva, Switzerland. 2007.

ISO. ISO 10312: Ambient air -- Determination of asbestos fibres -- Direct transfer transmission electron microscopy method. 1995.

ISO. ISO 13794: Ambient air - Determination of asbestos fibres - Indirect-transfer transmission electron microscopy method. 1999.

Kumagai S, Kurumatani N. Asbestos fiber concentration in the area surrounding a former asbestos cement plant and excess mesothelioma deaths in residents. Am J Ind Med. 2009;52(10): 790-798. Available from: doi:10.1002/ajim.20743. 
Kurumatani N, Kumagai S. Mapping the risk of mesothelioma due to neighborhood asbestos exposure. American Journal of Respiratory and Critical Care Medicine. 2008;178: 624-629. Available from: doi:10.116/rccm.200801-0630C.

Magnani C, Dalmasso P, Biggeri A, Ivaldi C, Mirabelli D, Terracini B. Increased risk of malignant mesothelioma of the pleura after residential or domestic exposure to asbestos: A casecontrol study in Casale Monferrato, Italy. Environmental Health Perspectives. 2001;109(9): 915-919. Available from: doi:10.1289/ehp.01109915.

Magnani C, Terracini B, Ivaldi C, Botta M, Mancini A, Andrion A. Pleural malignant mesothelioma and non-occupational exposure to asbestos in Casale Monferrato, Italy. Occup Environ Med. 1995;52(6): 362-367. Available from: doi:10.1136/oem.52.6.362.

Mensi C, Riboldi L, De Matteis S, Bertazzi P, Consonni D. Impact of an asbestos cement factory on mesothelioma incidence: Global assessment of effects of occupational, familial, and environmental exposure. Environ Int. 2015;74: 191-199. Available from: doi:10.1016/j.envint.2014.10.016.

MesaLabs. Defender 500 Series. User Manual. 2015.

MinEducación. Calendario y jornada escolar en Colombia. Available from: https://www.mineducacion.gov.co/1759/w3-article-364691.html. [Accessed February 2019].

Musti M, Pollice A, Cavone D, Dragonieri S, Bilancia M. The relationship between malignant mesothelioma and an asbestos cement plant environmental risk: a spatial case-control study in the city of Bari (Itali). Int Arch Occup Environ Health. 2009;82(4): 489-497. Available from: doi:10.1007/s00420-008-0358-5.

NIOSH. 7400 Asbestos and other fibers by PCM. Available at: http://www.cdc.gov/niosh/docs/2003-154/pdfs/7400.pdf. 1994.

Ramos-Bonilla JP, Cely-García MF, Giraldo M, Comba P, Terracini B, Pasetto R, Marsili D, Ascoli V, Lysaniuk B, Rodríguez MC, Mazzeo A, López-Panqueva RP, Baldión M, Cañón D, GarcíaHerreros LG, Pinzón B, Hernández LJ, Silva, YA. An asbestos contaminated town in the vicinity of an asbestos-cement facility: the case study of Sibaté, Colombia. Environmental Research. 2019;176:108464. [Epub ahead of print]. Available from: doi:https://doi.org/10.1016/j.envres.2019.04.031.

Ryan PH, LeMasters GK, Burkle J, Lockey JE, Black B, Rice C. Childhood exposure to Libby amphibole during outdoor activities. J Expo Sci Environ Epidemiol. 2015;25(1): 4-11. Available from: doi: 10.1038/jes.2013.26.

Salazar N, Cely-García MF, Breysse PN, Ramos-Bonilla JP. Asbestos Exposure among Transmission Mechanics in Automotive Repair Shops. Ann Occup Hyg. 2014;59(3): 292-306. Available from: doi:10.1093/annhyg/meu093. [Epub ahead of print].

Savitz DA. Commentary: Response to Environmental Pollution. More Research May Not Be Needed. Epidemiology. 2016;27(6): p. 919-920. Available from: doi: 10.1097/EDE.0000000000000526.

Turci F, Favero-Longo SE, Gazzano C, Tomatis M, Gentile-Garofalo L, Bergamini M. Assessment of asbestos exposure during a simulated agricultural activity in the proximity of the former asbestos mine of Balangero, Italy. J Hazard Mater. 2016;308: 321-327. Available from: doi: 10.1016/j.jhazmat.2016.01.056.

Virta RL. Mineral Commodity Profiles - Asbestos. Circular 1255-KK. USGS. 2005. p. 1-63.

WHO. Chrysotile Asbestos. 2014. p. 1-52. Available from https://www.who.int/ipcs/assessment/public health/chrysotile asbestos summary.pdf 
Wroble J. Environmental Monitoring for Asbestos: Sumas Mountain Asbestos Site, Selected Residential Properties. Bulk Sampling and Analysis, Activity Based Sampling, Surface Water Sampling. U.S. EPA. 2010. p. 1-133.

Wroble J, Frederick T, Frame A, Vallero D. Comparison of soil sampling and analytical methods for asbestos at the Sumas Mountain Asbestos Site - Working towards a toolbox for better assessment. PLoS One. 2017;12(7): e0180210. Available from:

doi:https://doi.org/10.1371/journal.pone.0180210. 